\title{
Response of sows to oestradiol benzoate treatment after weaning at two stages of lactation
}

\author{
S. Edwards* and G. R. Foxcroft \\ A.R.C. Group on Hormones and Farm Animal Reproduction-University of Nottingham Faculty of \\ Agricultural Sciences, Sutton Bonington, Loughborough LE12 5RD, U.K.
}

\begin{abstract}
Summary. The timing and dosage of oestradiol benzoate injected after weaning was critical with respect to the pattern of behavioural oestrus and the ovarian stimulation achieved; treatment on the day of weaning (Day 0 ) and Day 1 with $60 \mu \mathrm{g}$ oestradiol benzoate/ $\mathrm{kg}$ body wt produced poor ovulatory responses and abnormal oestrous behaviour. Treatment on Day 2 with $30 \mu \mathrm{g}$ oestradiol benzoate $/ \mathrm{kg}$ resulted in consistent oestrus and ovulatory responses although the ovulation rates $(10 \cdot 6 \pm 1 \cdot 1$ in 3 -week and $12 \cdot 2 \pm 1 \cdot 7$ in 5-week weaned sows) were below those expected in fertile untreated sows weaned at these times. The timing of the preovulatory LH surge $(53.6 \pm 2 \mathrm{~h}$ after oestradiol benzoate) was closely synchronized in all sows and a similar synchronous rise in plasma progesterone concentrations $100 \pm 4 \mathrm{~h}$ after oestradiol benzoate suggests a similar synchrony of ovulation. The magnitude of the LH and FSH responses to oestradiol benzoate were similar to those that occur in untreated sows and similar differences also existed in gonadotrophin secretion related to the length of lactation.
\end{abstract}

\section{Introduction}

Lactation in the pig is a period which is usually associated with anoestrus and anovulation. Weaning the piglets results in a rapid increase in follicular growth which terminates in overt oestrus and ovulation some 5-10 days later (Burger, 1952). A proportion of sows, however, fail to show oestrus for a much longer period after weaning and thus decrease the productive efficiency of the herd. A large degree of variation in the weaning to oestrus interval in a herd results in reduced productivity because good conception rates require good service management which is not possible when service procedures interfere with other stock tasks. The variation in the weaning to oestrus interval is increased as duration of lactation is shortened (Self \& Grummer, 1958; Smidt, Scheven \& Steinbach, 1965; van der Heyde, 1972; Cole, Varley \& Hughes, 1975). Exogenous hormone therapy as a means of inducing oestrus during lactation has had limited success and has often involved a series of injections which is both time consuming and impractical (Cole \& Hughes, 1946; Heitman \& Cole, 1956; Crighton, 1970; Guthrie, Pursel \& Frobish, 1978). The treatment of sows with gonadotrophins and steroids at, or shortly after, weaning has been more successful. Weaning to oestrus intervals have been shortened by use of diethylstilboestrol (Rigor, Villareal \& Illagan, 1968) or a combination of steroids (Schmidt, Jochle \& Thume, 1968; Dyck, Palmer \& Simarks, 1979) but conception rates and litter size were reduced. Gonadotrophin therapy (PMSG : hCG combinations) can shorten the weaning to oestrus interval with no detrimental effects on fertility (Rasbech, 1953; Whyte, 1977).

* Present address: The Agricultural Institute, Grange, Dunsany, Co. Meath, Ireland. 
In this study we examined the effects of using oestradiol benzoate in weaned sows as a substitute for the naturally occurring rise in oestrogens which occurs before oestrus (Edwards \& Foxcroft, 1983) and monitored the endocrine consequences of such treatment after weaning at two stages of lactation.

\section{Materials and Methods}

\section{Experimental procedures}

Experiment 1. Oestradiol benzoate in ethyl oleate was administered by intramuscular (i.m.) injection at a dose of $60 \mu \mathrm{g} / \mathrm{kg}$ body weight at $09: 00$ to $09: 30 \mathrm{~h}$ to 3 sows on the day of weaning (Day $0), 2$ sows on Day 1 and 1 sow on Day 2 after a 5-week lactation. Day-0 sows were fitted with a jugular venous cannula before weaning and were not tested for oestrus with a boar. Blood samples were withdrawn at 4-h intervals between $08: 00$ and 24:00 h for 12 days. An additional sample was also taken at $04: 00 \mathrm{~h}$, about $68 \mathrm{~h}$ after injection, and animals were slaughtered 7-8 days after treatment. Day 1 and Day 2 sows were not cannulated; they were tested daily for oestrus with an intact boar and slaughtered 2-3 days post coitum. The ovaries of all sows were checked for evidence of ovulation and when appropriate the oviducts were flushed with isotonic saline before examination of the eggs for evidence of fertilization and normal development.

Experiment 2. A total of 13 sows due to be culled on the basis of unacceptable reproductive performance (usually low litter size and/or age) and weaned after 5-weeks of lactation were similarly injected with oestradiol benzoate at $09: 00$ to $09: 30 \mathrm{~h}$ but at a dose of $30 \mu \mathrm{g} / \mathrm{kg}$ body weight 1 or 2 days after weaning. These sows were tested for oestrus by daily exposure to an intact boar and were slaughtered at various intervals post coitum. The reproductive tracts were examined for the presence of ova or embryos and fertilization and normal cleavage of ova and embryonic size in utero were used to establish the viability of the embryos recovered.

Experiment 3. A total of 14 fertile breeding sows were fitted with a jugular venous cannula on the day of weaning, which was at $3(\mathrm{~N}=7)$ or $5(\mathrm{~N}=7)$ weeks of lactation, and injected i.m. with oestradiol benzoate at $30 \mu \mathrm{g} / \mathrm{kg}$ at $09: 00 \mathrm{~h}$ on Day 2. Sows were not tested for oestrus with a boar and blood sampling began at 08:00 h on Day 1 and continued until at least Day 10. Samples were withdrawn at 4-h intervals between $08: 00$ and 24:00 h except on Day 5 (approximately $68 \mathrm{~h}$ after injection) when a sample was also taken at $04: 00 \mathrm{~h}$. After blood sampling all sows were slaughtered and their ovaries examined for evidence of ovulation.

\section{Assay procedures}

Blood samples were analysed for LH (Foxcroft, Pomerantz \& Nalbandov, 1975), FSH and oestradiol-17 (Foxcroft, Elsaesser, Stickney, Back \& Haynes, 1983) and progesterone (Haresign, Foster, Haynes, Crighton \& Lamming, 1975) by previously validated radioimmunoassays. Interand intra-assay coefficients of variation (CV) were 12 and $6 \%$ and 15 and $4 \%$ for $\mathrm{LH}$ and FSH respectively. Inter- and intra-assay $\mathrm{CVs}$ for oestradiol- $17 \beta$ were $<10 \%$ with an average recovery of steroid from plasma of $94.7 \pm 0 \cdot 8 \%$. Oestradiol values were not corrected for recovery losses. Interand intra-assay CVs for progesterone were 10 and $14 \%$ and recovery of steroid from plasma averaged $65 \cdot 5 \pm 2 \cdot 1 \%$ and values were corrected for recovery losses. Assay sensitivities (minimum detectable amount) were $1.0 \mathrm{ng} \mathrm{LH} / \mathrm{ml}, 10 \mathrm{pg}$ oestradiol $-17 / 3 / \mathrm{ml}, 0.8 \mathrm{ng}$ progesterone $/ \mathrm{ml}$ and $30 \mathrm{ng}$ $\mathrm{FSH} / \mathrm{ml}$.

\section{Statistical analysis}

All differences between means were analysed by Student's $t$ test. 


\section{Results}

\section{Experiments 1 and 2}

The injection of oestradiol benzoate on the day of weaning induced a very weak oestrus 3 days later as determined visually and with haunch testing. At slaughter the sows showed no evidence of ovulation and very little follicular development. Although analysis of the endocrine profiles from these sows showed that plasma FSH and LH concentrations did not rise at weaning, a highly synchronized preovulatory-type LH/FSH surge occurred. Mean ( \pm s.e.) LH peak levels of $12.4 \pm$ $2.5 \mathrm{ng} / \mathrm{ml}$ were observed $63.3 \pm 2 \mathrm{~h}$ after oestradiol benzoate and the duration of the surges ranged from 24 to $34 \mathrm{~h}$. After the preovulatory FSH discharge, plasma FSH concentrations remained low until the end of the blood sampling period. Peak plasma levels of oestradiol were very high ( $285 \pm$ $29 \mathrm{pg} / \mathrm{ml}$ ) and were attained $27 \pm 8 \mathrm{~h}$ after the injection of oestradiol benzoate; concentrations declined to $40-50 \mathrm{pg} / \mathrm{ml}$ (still in the high physiological range) by 7 days after the injection. Plasma concentrations of progesterone were basal $(<1.0 \mathrm{ng} / \mathrm{ml})$ throughout the sampling period.

One of the sows treated on Day 1 and the sow treated on Day 2 ovulated and formed 10 and 9 corpora lutea respectively. The remaining data from Exp. 2 are summarized in Table 1. Ovulation rates in sows treated on Day 1 were very variable and in 2 animals it appeared that oestradiol benzoate treatment almost totally inhibited follicular development. In each of 2 sows there were 11 $\mathrm{CL}$, an ovulation rate consistent with previous reproductive performance, and in the remaining sows the CL numbers of 20 and 21 would be consistent with acceptable fertility in practice; in one of these sows 17 normally developing tubal eggs were recovered at slaughter. Ovulation rates in the sows given oestradiol benzoate on Day 2 were more uniform with no suggestion of a total inhibition of follicular development. In 3 sows (Or217, D17, LW6) acceptable ovulation rates were associated with the recovery of low numbers of tubal eggs and viable embryos and this high level of embryonic mortality would be consistent with the previous poor fertility of these sows. In 2 sows (A15, D15), however, fertilization and normal early development was observed for $100 \%$ of ova shed, although the ovulation rates of 10 and 13 in these animals are below those needed to ensure acceptable litter sizes at term when compared to highly fertile breeding sows.

Table 1. A summary of the fertility data after oestradiol benzoate (OB) treatment at $30 \mu \mathrm{g} / \mathrm{kg}$ on Day 1 or 2 in 5 -week weaned sows

\begin{tabular}{|c|c|c|c|c|c|c|c|c|}
\hline Sow & $\begin{array}{c}\text { Day of } \mathrm{OB} \\
\text { treatment }\end{array}$ & $\begin{array}{c}\text { Day of } \\
\text { slaughter } \\
\text { p.c. }\end{array}$ & $\begin{array}{c}\text { No. of } \\
\text { CL }\end{array}$ & $\begin{array}{l}\text { Nos ova/ } \\
\text { embryos } \\
\text { recovered }\end{array}$ & $\begin{array}{c}\text { No. of } \\
\text { ova } \\
\text { fertilized }\end{array}$ & $\begin{array}{l}\text { No. of implanted } \\
\text { and normally } \\
\text { developed } \\
\text { embryos }\end{array}$ & $\begin{array}{c}\text { Previous } \\
\text { live litter } \\
\text { size } \\
\text { (mean } \pm \text { s.e.m.) }\end{array}$ & $\begin{array}{c}\text { No. of } \\
\text { previous } \\
\text { litters }\end{array}$ \\
\hline W206 & +1 & 30 & 0 & 0 & - & - & $13.0 \pm 1.4$ & 6 \\
\hline Ye71 & +1 & 12 & 2 & 1 & - & 1 & $9 \cdot 3 \pm 1.0$ & 9 \\
\hline G216 & +1 & 6 & 11 & 10 & 0 & $\ldots^{*}$ & $10 \cdot 3 \pm 0.7$ & 9 \\
\hline Ye32 & +1 & 3 & 21 & 17 & 10 & - & $10.9 \pm 0.6$ & 9 \\
\hline BL200 & +1 & 30 & 11 & 11 & - & 10 & $10 \cdot 5 \pm 0.3$ & 10 \\
\hline Or201 & +1 & 3 & 20 & 19 & 17 & - & $11.6 \pm 0.7$ & 8 \\
\hline BL208† & +2 & - & - & - & - & & $10 \cdot 3 \pm 0.7$ & 9 \\
\hline BL228 & +2 & 12 & 13 & $-\ddagger$ & $\ddagger$ & & $10.5 \pm 0.8$ & 8 \\
\hline Or 217 & +2 & 3 & 20 & 8 & 8 & - & $8.9 \pm 1.2$ & 7 \\
\hline D17 & +2 & 29 & 17 & 5 & - & 5 & $8.0 \pm 1.0$ & 2 \\
\hline LW6 & +2 & 30 & 14 & 8 & - & 6 & $5 \cdot 0 \pm 0.0$ & 2 \\
\hline A 15 & +2 & 3 & 10 & 10 & 10 & - & $9 \cdot 5 \pm 3.5$ & 2 \\
\hline D15 & +2 & 3 & 13 & 13 & 13 & - & $9.5 \pm 1.5$ & 2 \\
\hline
\end{tabular}

* Incomplete service.

$\uparrow$ Not mated because of hind-leg infirmity.

$\ddagger$ Boar failed to mate. 


\section{Experiment 3}

Oestradiol benzoate treatment Day 2 after weaning at 3- or 5-weeks post partum resulted in oestrus $2-4$ days after treatment in $13 / 14$ sows. The sow that did not respond was in oestrus at the time of weaning. Ovulation rates, although variable, were not significantly different $(P>0.05)$ $(10.6 \pm 1.1$ in 3 -week and $12.2 \pm 1.7$ in 5 -week weaned animals).

A complete analysis of the endocrine profiles from 12 sows showed that plasma oestradiol levels after injection varied between 81 and $287 \mathrm{pg} / \mathrm{ml}$ (mean \pm s.e.m. $158 \pm 18 \mathrm{pg} / \mathrm{ml})$ and reached a peak 3-47 $(21 \pm 4) \mathrm{h}$ after injection (see Text-fig. 1). Thereafter, concentrations gradually declined and were usually basal by 8 days after injection. Measurable levels of $\mathrm{LH}$ were present in most sows in the period between weaning and oestradiol benzoate injection (Text-fig. 1). Oestradiol benzoate injection was immediately followed by a period of suppressed LH levels in 10/12 animals and this generally prevailed throughout Day 2 before the preovulatory LH surge during the last part of Day 3 or early on Day 4. Maximal LH concentrations occurred 53.6 $\pm 2.0 \mathrm{~h}$ after oestrogen injection and returned to basal values by Day 6 in all animals. By Day 10 elevated levels of LH in some samples suggested that luteal-phase episodic LH secretion was present in 7/12 sows. Quantitative examination of the LH surge data indicated a significant difference between 5- and 3-week weaned sows in terms of maximal LH concentrations $(22.6 \pm 3.2$ and $9.0 \pm 1.0 \mathrm{ng} / \mathrm{ml}$ respectively; $P<$ $0.01)$ and total LH secreted in the surge $(1283 \pm 120$ and $623 \pm 97$ arbitrary units of area under the curve, respectively; $P<0.001$ ).

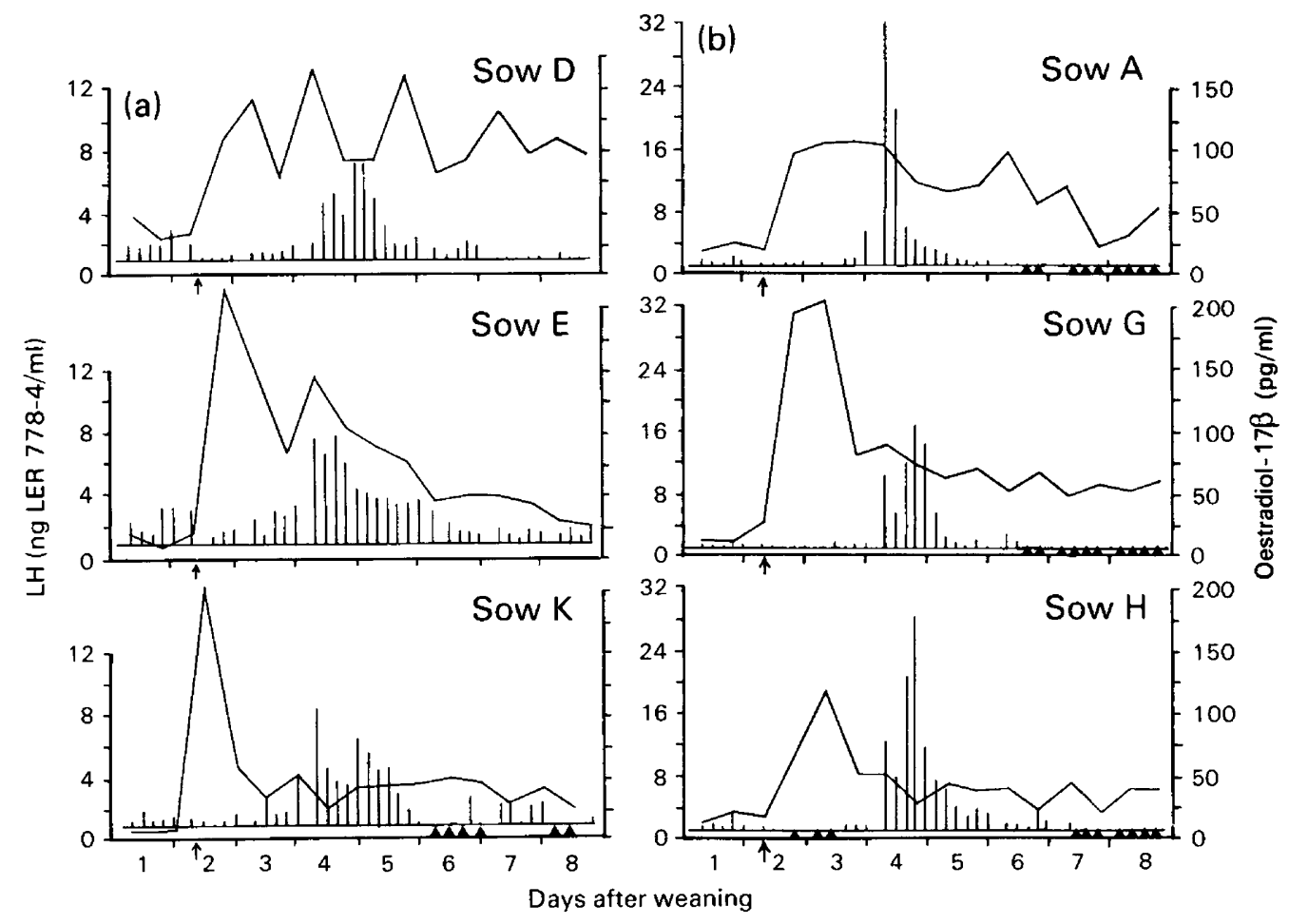

Text-fig. 1. Oestradiol-17 $(-)$ concentrations and the $\mathrm{LH}$ responses (vertical bars) in representative sows weaned at (a) 3 weeks and (b) 5 weeks of lactation and after injection (arrow) with oestradiol benzoate. Concentrations indicated by $\boldsymbol{\Delta}$ were below the sensitivity of the assay. Note the LH scale difference of the 5-week weaned sows. 
Absolute concentrations of FSH varied markedly between animals but in the period between oestradiol benzoate injection and the preovulatory LH surge FSH concentrations were declining in the 5-week weaned animals whilst no consistent changes occurred at this time in the 3-week weaned sows (Text-fig. 2). In the 5-week weaned sows the preovulatory LH surge was accompanied by elevated FSH levels in $5 / 6$ animals, whilst only $1 / 6$ of the 3-week weaned animals showed this response. Days 6 and 7 after weaning (immediately after the LH surge) were characterized by suppressed FSH levels in both groups of sows whilst throughout Days 8, 9 and 10 FSH concentrations increased.

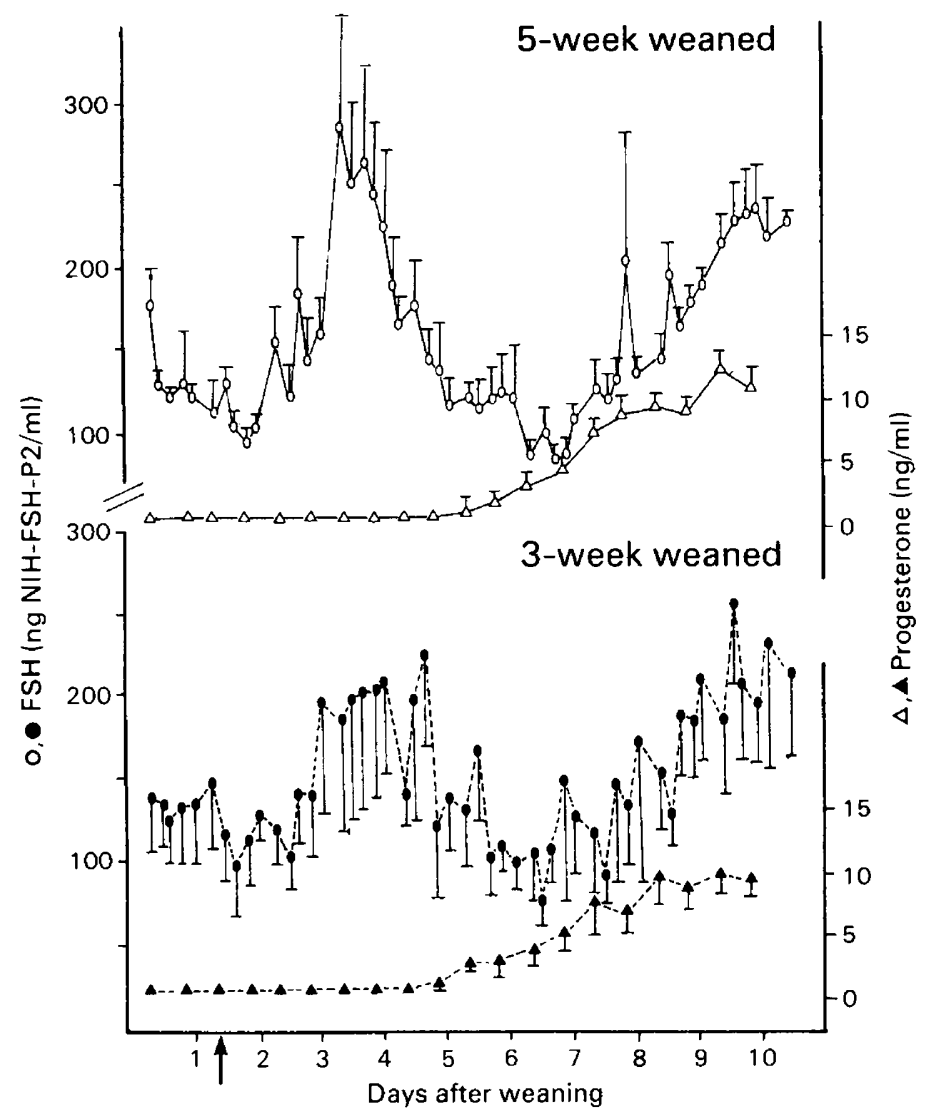

Text-fig. 2. Mean plasma FSH and progesterone concentrations after injection of oestradiol benzoate (arrow) 2 days after weaning at 3 and 5 weeks post partum.

Progesterone concentrations were basal $(<1.5 \mathrm{ng} / \mathrm{ml})$ in all sows in the days after weaning and began to rise on Day 6, indicating the onset of luteal function. This rise was strikingly synchronized and followed oestradiol benzoate injection by $100 \pm 4 \mathrm{~h}$. Throughout the remainder of the sampling period progesterone concentrations gradually increased to an overall mean value of $13.8 \pm 1.2$ $\mathrm{ng} / \mathrm{ml}$ and no differences were observed in progesterone secretion between the groups.

\section{Discussion}

These results indicate that oestradiol benzoate treatment is capable of inducing an early, synchronous and predictable return to oestrus and ovulation in the weaned sow when given at an appropriate time. The majority of sows treated two days after weaning with $30 \mu \mathrm{g}$ oestradiol 
benzoate $/ \mathrm{kg}$ body weight returned to oestrus on or before Day 5 , a time which compares favourably with the mean of 7.85 days recorded by Burger (1952) for Large White sows and with the results obtained in many commercial herds employing 3-week weaning (M.L.C., 1980). Although the interval of 3 days from oestradiol benzoate injection to overt oestrus in sows injected with $30 \mu \mathrm{g} / \mathrm{kg}$ on Day 2 is in agreement with published data (Rasbech, 1953; Dyck et al., 1979), the marked reduction in fertility and prolonged oestrous periods associated with the previous use of synthetic oestrogens (de la Cerna, 1956; Rigor et al., 1968; Schmidt et al., 1968) were not observed.

The interval from weaning to oestradiol benzoate injection had a significant effect on the potential fertility of the sows in the present study. Injection of even a high dose of oestradiol benzoate on the day of weaning caused only a weak behavioural and visual oestrus 3 days later with no accompanying ovulation, whilst the same dose injected 1 or 2 days after weaning caused abnormal 'hyperactive' oestrous behaviour during which the sows were very excited and agitated and would not stand to be fully mated. Halving the dose of oestradiol benzoate removed these behavioural aberrations and produced a very strong standing oestrous response.

The reasons for the variability in ovarian responses to oestrogen treatment at different times after weaning are probably related to the patterns of gonadotrophin secretion present before treatment. Oestradiol benzoate treatment was, however, effective in stimulating the positive feedback mechanism to produce an LH surge and in inducing ovulation when given 2 days after weaning. Both the magnitude of the oestradiol benzoate-induced gonadotrophin responses and the differences between the 3- and 5-week weaned sows in the pattern of LH and FSH secretion were similar to those observed in untreated animals (Edwards \& Foxcroft, 1983). In addition to providing further evidence for an impairment of hypothalamic-pituitary activity with shortened lactations, this also demonstrates that the reduced ovulation rates after oestradiol benzoate treatment (12.2 at 5-weeks, 10.6 at 3-weeks compared to $17 \cdot 3$ at 5-weeks and 15.2 at 3-weeks in untreated sows: Edwards \& Foxcroft, 1983) were not related to an oestrogen-induced depression of the concentrations of LH and FSH during the preovulatory surge. Furthermore the present study indicates that any reduction in gonadotrophin secretion during the surge in early-weaned sows is not in itself due to inadequate levels of oestradiol in the early post-weaning period (Edwards \& Foxcroft, 1983).

However, oestradiol treatment at or immediately after weaning did suppress the rise in basal LH secretion previously observed in untreated sows and as this rise in $\mathrm{LH}$ is postulated to be a major component of the trigger for follicular development, its complete or partial suppression probably limits follicular development and results in the observed reduction in ovulation or complete absence of follicular growth. Delaying treatment to Day 2 allows an adequate period of follicular stimulation such that ovulation rates at the synchronized oestrus are only marginally reduced when compared to those for untreated sows.

The suppression of FSH concentrations after the preovulatory gonadotrophin surge is atypical of untreated cyclic or weaned sows (Wilfinger, 1974; Edwards \& Foxcroft, 1983). This suppression was removed by Day 10, when plasma oestrogen concentrations had returned to basal values, and a potent negative feedback effect, due to the persistently elevated levels of oestrogen, therefore appears to exist after oestradiol benzoate treatment. The onset of the LH surge is usually associated with a rapid decline in endogenous oestradiol secretion resulting in an absence of negative feedback at this time (van de Wiel, Erkens, Koops, Vos \& van Landeghem, 1981 ; Edwards \& Foxcroft, 1983; Foxcroft $\&$ van de Wiel, 1982). The consequences of this suppression are unknown, but it has been suggested that FSH secretion in this period may initiate or accelerate the growth of the next crop of follicles (Wilfinger, 1974). If this is the case, then the suppression of FSH secretion associated with the present oestradiol benzoate regimen may lead to adverse responses if the sow returns to oestrus. Since all sows so far mated have conceived successfully this possibility has not been tested. Rasbech (1953) has shown that diethylstilboestrol treatment of weaned sows had a detrimental effect on conception rates at subsequent oestrous periods if conception did not occur at the induced oestrus, but no such effects were manifested when natural gestrogens were used, 
The present study has therefore not only increased our limited knowledge of the basic endocrine interrelationships which control the return to oestrus after weaning but has also demonstrated the potential for the use of exogenous oestrogen in the weaned sow to synchronize the time of the preovulatory $\mathrm{LH}$ surge and hence ovulation. In this respect oestradiol benzoate treatment appears to have a potential application in commercial practice, in particular in those herds using artificial insemination although there is a consistent reduction in ovulation rate which could lead to unacceptably small litter sizes at term. However, the post-treatment concentrations of plasma oestradiol- $17 \beta$ in the present studies were significantly higher at both dose levels of oestradiol benzoate employed than those previously reported for untreated cyclic and weaned sows in the preovulatory period (Shearer, Purvis, Jenkin \& Haynes, 1972; van de Wiel et al., 1981; Edwards \& Foxcroft, 1983), and a further reduction in the dose of oestradiol benzoate might minimize any detrimental side effects without causing a diminished ovuiatory response.

We thank Dr G. D. Niswender and Professor W. R. Butt for gifts of antiserum and NIH, Bethesda, Maryland for gifts of purified hormone preparations. This work was carried out under research grants provided by the Meat and Livestock Commission to whom one of us (S.E.) is indebted for financial support.

\section{References}

Burger, J.F. (1952) Sex physiology of pigs. Onderstepoort J. vet. Res., Suppl. 2, 3-218.

Cole, H.H. \& Hughes, E.H. (1946) Induction of oestrus in lactating sows with equine gonadotropin. J. Anim. Sci. 5, 25-29.

Cole, D.J.A., Varley, M.A. \& Hughes, P.E. (1975) Studies in sow reproduction. 2 . The effect of lactation length on the subsequent reproductive performance of the sow. Anim. Prod. 20, 401-406.

Crighton, D.B. (1970) Induction of pregnancy during lactation in the sow. J. Reprod. Fert. 22, 223-231.

de la Cerna, G. (1956) Preliminary report on the use of diethylstilbestrol in delayed oestrus in swine. Phillipine J. Anim. Industry 17, 105-111.

Dyck, G.W., Palmer, W.M. \& Simarks, S. (1979) Post weaning plasma concentrations of $\mathbf{L H}$ and oestrogen in sows: effect of treatment with pregnant mare's serum gonadotrophin or oestradiol-17 $\beta$ plus progesterone. Can. J. Anim. Sci. 59, 159-166.

Edwards, S. \& Foxcroft, G.R. (1983) Endocrine changes in sows weaned at two stages of lactation. $J$. Reprod. Fert. 67, 161-172.

Foxcroft, G.R. \& van de Wiel, D.F.M. (1982) Endocrine control of the oestrous cycle. In Control of Pig Reproduction, Ch. 8, pp. 161-177. Eds D. J. A. Cole \& G. R. Foxcroft. Butterworths, London.

Foxcroft, G.R., Pomerantz, D.K. \& Nalbandov, A.V. (1975) Effects of estradiol-17 $\beta$ on LH-RH/FSH-RHinduced, and spontaneous, LH release in prepubertal female pigs. Endocrinology 96, 551-557.

Foxcroft, G.R., Elsaesser, F., Stickney, K., Back, H.L. \& Haynes, N.B. (1983) Ovarian oestrogen-dependant maturation of the LH/FSH surge mechanism during prepubertal development in the gilt. $J$. Endocr. (in press).

Guthrie, H.D., Pursel, V.G. \& Frobish, L.T. (1978) Attempts to induce conception in lactating sows. $J$. Anim. Sci. 47, 1145-1151.
Haresign, W., Foster, J.P., Haynes, N.B., Crighton, D.B. \& Lamming, G.E. (1975) Progesterone levels following treatment of seasonally anoestrous ewes with synthetic LH-releasing hormone. J. Reprod. Fert. 43, 269-279.

Heitman, H. \& Cole, H.H. (1956) Further studies in the induction of estrus in lactating sows with equine gonadotropin. J. Anim. Sci. 15, 970-977.

Meat \& Livestock Commission (1980) Pig Improvement Services Newsletter No. 14.

Rasbech, N.O. (1953) Studies on the employment of aphrodisiacs for gilts and sows. Heat-promoting effects and size of litter in 1655 animals treated. Nord. VetMed. 5, 131-148.

Rigor, E.M., Villareal, R.L. \& Illagan, H.P. (1968) Oestrus induction in sows with diethylstilbestrol. Proc. 6th Int. congr. Anim. Reprod. \& A.I., Paris 2, 1519-1521.

Schmidt, D., Jochle, W. \& Thume, O. (1968) Heat synchronization by androgen-oestrogen combinations in sows and gilts. Proc. 6th Int. Congr. Anim. Reprod. \& A.I., Paris 2, 1523-1526.

Self, H.L. \& Grummer, R.H. (1958) The rate and economy of pig gains and the reproductive behavior in sows when litters are weaned at 10 days, 21 days or 56 days of age. J. Anim. Sci. 17, 862-868.

Shearer, I.J., Purvis, K., Jenkin, G. \& Haynes, N.B. (1972) Peripheral plasma progesterone and oestradiol-17 $7 \beta$ before and after puberty in gilts. $J$. Reprod. Fert. 30, 347-360.

Smidt, D., Scheven, B. \& Steinbach, J. (1965) The influence of lactation on the sexual functions of sows. Zuchtungskunde 37, 23-36.

van der Heyde, H. (1972) A practical assessment of early weaning. Proc. Br. Soc. Anim. Prod. 1, 33-36.

van de Wiel, D.F.M., Erkens, J., Koops, W., Vos, E. \& van Landeghem, A.A.J. (1981) Periestrous and midluteal time courses of circulating LH, FSH, prolactin, 
estradiol- $17 \beta$ and progesterone in the domestic pig. Biol. Reprod. 24, 223-233.

Whyte, P.B.D. (1977) The induction of oestrus in recently weaned sows with low doses of gonadotrophins. J. S. Afr. vet. Ass. 48, 129-131.
Wilfinger, W.W. (1974) Plasma concentrations of LH, FSH and prolactin in ovariectomized and intact swine. Diss. Abstracts 35, 2985-B.

Received 2 June 1982 